\title{
Composition and Thermal Behavior of Oils from Native Seeds and Fruits of Argentina and Uruguay
}

\author{
María Antonia Grompone ${ }^{1}$, Bruno Irigaray ${ }^{1}$, Denisse Rodríguez ${ }^{2}$, Silvia Maidana ${ }^{2}$ and Norma Sammán ${ }^{2}$ \\ 1. Departamento de Ciencia y Tecnología de los Alimentos, Facultad de Química, Universidad de la República, Montevideo, Gral. \\ Flores 2124, Uruguay \\ 2. Departamento Bioquímica de la Nutrición, Instituto Superior de Investigaciones Biológicas (INSIBIO), Universidad Nacional de \\ Tucumán, Tucumán, Chacabuco 461, Argentina
}

\begin{abstract}
The purpose of this work was to study the thermal characterization of oils extracted from native seeds and fruits of the Argentina, Uruguayan region. This is important because it's necessary to find new applications for food industry. Uruguayan wild cardoon seed, Argentinian wild papaya seeds, Argentinian avocado pulp, Argentinian cherimoya seeds, Argentinian grapeseeds and four commercial brands of chia oils were studied. The thermal behaviors of the oils were analyzed on a differential scanning calorimetry (DSC), TA Instrument, Q20 model equipped with an intercooler. These oils' thermal profiles presented differences, which are related to the compositions of fatty acids and triacylglycerols. The thermogram for the chia oil, with a high content of linolenic acid, presented a very important peak at about $-40{ }^{\circ} \mathrm{C}$; whereas, the papaya oil with an oleic acid content of $74 \%$, showed a peak at about $-3{ }^{\circ} \mathrm{C}$. When comparing the thermal behaviors of these oils to commercial brand oils, it was found that the chia oil is similar to the flaxseed oil, the papaya similar to the olive oil and the avocado similar to the rice bran oil. The avocado oil, in particular, presents high solid content at cold store or winter temperatures, which would make its use in those conditions difficult (for example, a cosmetic cream or gourmet oil). In conclusion, the thermal behavior of one oil sample as determined by DSC provides valuable information with regards to the possible use of new oils of American origin as replacement of usual commercial others.
\end{abstract}

Key words: South American oils, thermal behavior, DSC.

\section{Introduction}

Chia (Salvia hispanica L.) is an annual, summer, herbaceous plant from the Labiatiae family. It is native to Central and Southern Mexico and Guatemala; it has been used and grown since 3,500 BC. This plant produces numerous small seeds, mostly dark in color, which contain oil in the 25\%-39\% rank. This oil contains over $60 \%$ of acid linolenic, thus making it an important source of fatty acids of the omega-3 family [1-8].

The avocado (Persea americana Mill.) belongs to the Lauraceae family. This family includes approximately 150 species, most of which grow in American tropical regions. The fruit is high in lipid content and consumed as food. The oil extracted from

Corresponding author: Bruno Irigaray, Ph.D., research fields: fats and oils. E-mail: birig@fq.edu.uy. the pulp is used in food, pharmaceutical and cosmetic preparations. It is very high in oleic acid: $44 \%-74 \%$ [9-18].

The papaya (Carica papaya L.) is original from Central America; the species belongs to the Caricaceae, a small family mostly from America and composed of six genera. The fruit is an oval shaped berry with pronounced furrows, very aromatic and its color is an intense yellow. The fruit's black seeds have a strong flavor; sometimes these are grinded and used as a black pepper substitute. The oil extracted from the seeds is very rich in oleic acid: 63\%-79\% [19-21].

The cherimoya (Annona cherimola Mill.) belongs to the Annonaceae family. Native to South America, it has been cultivated in the Peruvian Andes since the time of the Mochica culture. It was first introduced to Southern Spain before 1751, from where it was 
probably taken to Italy and Portugal. In the Mediterranean region, the cherimoya has adapted well in Israel, Egypt, Greece and Algeria. The fruit is green, large and fleshy, with a characteristically reticulated surface. The fruit's seeds are blackish, flattened, 1-1.5 $\mathrm{cm}$ in length. No reference to the oil extracted from these seeds has been found in the literature consulted.

The cardoon (Cynara cardunculus) is a member of the Asteraceae family, same as the artichoke (Cynara scolymus), of which it is sometimes considered a sub-specie. This plant is original from Europe, but does well in the fields of Chile, Argentina and Uruguay. It was accidentally introduced in South America in the mid 18th century, and possibly mixed in with wheat seeds to be planted. It is a perennial plant, vivacious, very invasive, with tuberous roots. The flowers are big and violet in color. The content of oil extracted varies between $18.5 \%$ and $25.3 \%$. The range of oleic acid content is highly variable: from $23.1 \%$ to $83.6 \%$ [22]. Other fatty acids that constitute the cardoon oil are linoleic and stearic acids, ranging from $40.0 \%$ to $61.5 \%$ and $18.0 \%$ to $45.0 \%$, respectively [22].

Grapeseed oil (Vitis vinifera) is a by-product of the wine and grape juice industry; it is sold as edible in several countries. This oil also has several uses in both the cosmetic and therapeutic industries. It is very rich in linoleic acid: 58\%-78\% [21, 23-28].

Knowing the thermal behaviors of the fatty materials, which is the variation in the content of solids at different temperatures, is key to defining some of their uses. Among the most frequent methods, the differential scanning calorimetry (DSC) has been employed for decades [29] and provides more complete information than other methods. The thermograms are useful for studying the continuous variation of the solid content with temperature (unlike the nuclear magnetic resonance, for example). There is little information in the literature on the relations between the position of the peaks in the thermograms and the predominant molecular species at each temperature. The difficulties in the correlation are great, as the triacylglycerols present different polymorphic shapes and their mixes render very complex phase diagrams due to their inter-solubility, compound formation, etc. [30].

The aim of this paper was to determine the composition of the fatty acids and thermal behaviors of the chia, cherimoya, papaya, avocado, cardoon and grapeseed oils, as there are no studies in this regard in the consulted bibliography. The oils studied are of additional interest, as they are from native plants of Argentina or Uruguay.

\section{Materials and Methods}

\subsection{Materials}

Uruguayan wild cardoon seeds (Cynara cardunculus), Argentinian wild papaya seeds (Carica papaya L.), avocado pulp (Persea americana Mill., Hass variety) from Purmamarca in the Argentinia province of Jujuy, Argentinian cherimoya (Annona cherimola Mill.) seeds from Palma Sola, also in Jujuy, and grapeseeds (Vitis vinifera) from a variety native to Jujuy were studied.

Four commercial brands of chia (Salvia hispanica L.) oils, labeled A, B, C and D, where A corresponds to the brand Veracruz, B corresponds to Sturla, C corresponds to America and D is unknown brand (Salta), were studied. Also studied were a commercial brand of extra virgin olive oil and refined commercial brands of regular sunflower, soybean, high oleic sunflower, rapeseed, rice bran and flaxseed oils.

\subsection{Methods}

\subsubsection{Extraction of the Oils}

Prior to the extraction, the seeds were dehydrated in a heater at $110^{\circ} \mathrm{C}$, grinded in a grinder and placed in paper filters. The oil was extracted using the Soxhlet method [31], using $60^{\circ}-80^{\circ}$ petroleum ether (quality for analysis). For the avocado oil, the extraction was performed on the pulp dehydrated by lyophilization. 


\subsubsection{Fatty Acid Composition}

The fatty acid composition of all of the mentioned oils was analyzed (in the form of methyl esters) in a Shimadzu 2010 plus chromatographer equipped with a Supelco SP 2330 capillary column and a FID 340. The injection was performed at $250{ }^{\circ} \mathrm{C}$ in split modality. The pressure was set at $60 \mathrm{Kpa}$ and the split relation was 80:1.

\subsubsection{Thermal Behavior}

The thermal behaviors of the oils were analyzed on DSC, TA Instruments brand, Q20 model equipped with an intercooler. An approximate of $15 \mathrm{mg}$ of each sample was weighed in an aluminum capsule. This was placed in a freezer for $48 \mathrm{~h}$. Afterward, the sample was analyzed on a DSC according to the following temperature program: the temperature was initially kept at $-60^{\circ} \mathrm{C}$ for $30 \mathrm{~min}$ and then elevated at a rate of $5^{\circ} \mathrm{C} / \mathrm{min}$ until reaching $60^{\circ} \mathrm{C}$.

\subsubsection{Oxidative Stability}

An Omnion brand oxidative stability instrument, model OSI-8, in which the temperature was set at $110{ }^{\circ} \mathrm{C}$ and pressure at $5.5 \mathrm{psi}$, was used to determine the oxidative stability of chia $\mathrm{C}$, flaxseed and extra virgin olive oils. The standard AOCS Cd-12b-92 [32] protocol was followed. Five grams of sample per tube were weighed and $50 \mathrm{~mL}$ of deionized water were placed in the conductivity cells.

\section{Results and Discussion}

The composition in principal fatty acids of the oils extracted is presented in Table 1. For comparison, the composition of commercial oils was added.

\subsection{Chia Oils of Different Origins}

In spite of having different origins, the four chia oil samples show a very similar composition in fatty acids (Table 1).

Fig. 1a shows the thermograms of chia oils. The vortex of the largest peak takes place at around $-40{ }^{\circ} \mathrm{C}$; the vortex of the second largest peak is at around $-5{ }^{\circ} \mathrm{C}$. The four samples show very similar thermal behavior, which is to expected given the similarities in the fatty acid composition. As a consequence, the study will be performed only with chia $\mathrm{C}$ oil.

Fig. $1 \mathrm{~b}$ shows the comparison of the thermal behavior of the chia $\mathrm{C}$ oil to flaxseed oil. Thermogram of chia oil is different from the flaxseed oil, even when the shape of the principal peak is similar (with a shoulder on the right); these are located in different temperature ranges. These differences might respond to the difference in fatty acid composition (Table 1), which would mean a different triacylglycerol composition.

Table 1 Principal fatty acid composition of extracted and commercial oils.

\begin{tabular}{lllllll}
\hline \multirow{2}{*}{ Oil } & \multicolumn{5}{c}{ Fatty acid composition } \\
\cline { 2 - 7 } & $16: 0$ & $16: 1$ & $18: 0$ & $18: 1$ & $18: 2$ & $18: 3$ \\
\hline Cherimoya & 16.7 & 2.9 & 6.2 & 47.0 & 25.2 & 0.9 \\
Papaya & 12.9 & 0.4 & 3.7 & 74.0 & 6.7 & 0.9 \\
Avocado & 21.4 & 11.5 & 0.5 & 56.0 & 10.0 & 0.6 \\
Grapeseed & 6.2 & & 6.0 & 15.3 & 70.6 & 1.2 \\
Cardoon & 11.4 & & 2.8 & 19.4 & 66.3 & 1.2 \\
Olive & 11.1 & 0.5 & 1.5 & 78.3 & 6.6 & 53.6 \\
Flaxseed & 5.7 & & 5.5 & 20.4 & 14.3 & 9.8 \\
Rapeseed & 3.8 & & 1.5 & 63.5 & 19.3 & 1.5 \\
Ricebran & 18.9 & & 1.8 & 42.5 & 32.3 & 0.3 \\
Sunflower & 5.4 & 3.0 & 45.8 & 44.9 & 0.1 \\
High oleic sunflower & 3.3 & 2.6 & 86.0 & 6.5 & 7.3 \\
Soybean & 10.4 & & 4.1 & 21.1 & 56.0 & 64.3 \\
Chia A & 6.9 & 3.2 & 6.9 & 19.0 & 66.7 \\
Chia B & 6.3 & 2.4 & 5.5 & 18.3 & 64.9 \\
Chia C & 6.3 & 2.1 & 5.7 & 20.1 & 63.7 \\
Chia D & 7.0 & 3.0 & 6.7 & 18.7 & \\
\hline
\end{tabular}




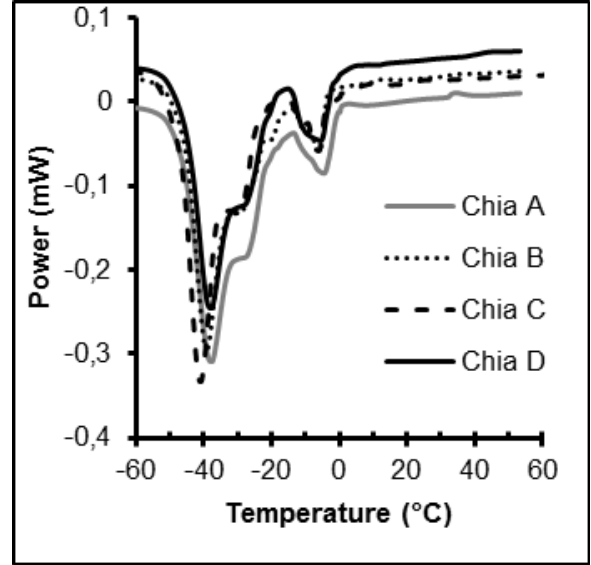

(a) Commercial chia seed olis

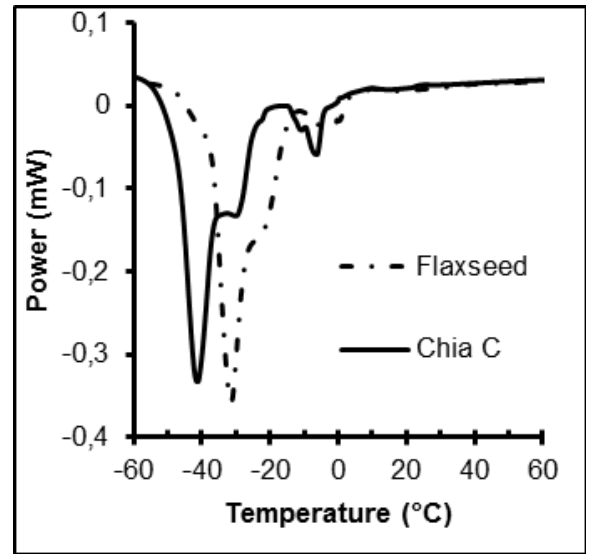

(b) Chia C oil

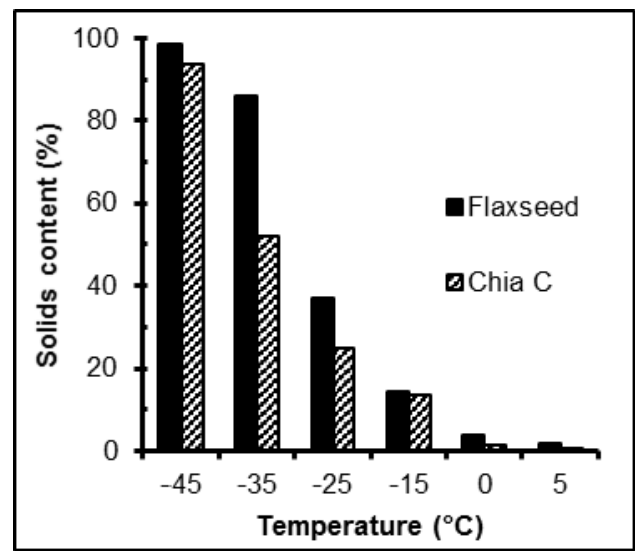

(c) Flaxseed oil

Fig. 1 Thermograms of chia seed and flaxseed oil and variation of their solid content with temperature.

To compare the thermal behavior of chia $\mathrm{C}$ oil with that of the flaxseed, the solid content for each oil sample was determined at previously established temperatures. Flaxseed shows a greater content of solids than the chia $\mathrm{C}$ oil at any temperature below
$-15{ }^{\circ} \mathrm{C}$ (Fig. 1c). Chia $\mathrm{C}$ oil has a greater content of linolenic acid than flaxseed oil, which would lead to a greater proportion of more polyunsaturated triacylglycerols (like 18:2/18:3/18:3 and 18:3/18:3/18:3) of lower melting points.

Even though both oils show different thermal behaviors at low temperatures, their solid content is similar starting at $-15{ }^{\circ} \mathrm{C}$ (Fig. 1c). When used at relatively low temperature, these oils behaved in the same way.

As a consequence, chia oil may be stored in a refrigerator, as it is not expected to partially crystallize (like other oils, such as rice bran or olive oil). This ensures better storage conditions (even when commercialized in capsules), since the oxidative stability of both is low due to its high unsaturation. The induction times obtained through the OSI method [32] were $0.8 \mathrm{~h}$ for chia oil and $2.0 \mathrm{~h}$ for flaxseed oil. As a reference, the OSI induction time of extra virgin olive oil was $40.3 \mathrm{~h}$.

\subsection{Avocado Pulp, Grapeseed, Cardoon, Cherimoya and Papaya Seed Oils}

Fig. 2a shows the thermograms of cardoon seeds oil superimposed on sunflower oil and in Fig. 2b superimposed on grapeseed oil. The cardoon seeds oil is richer in linoleic acid and poorer in oleic acid than sunflower oil (Table 1). This should lead to a greater content of more unsaturated triacylglycerols, which should cause the main peak of the thermogram to lean towards the lower temperatures and to have a more pronounced shoulder.

Content of polyunsaturated fatty acids (linoleic and linolenic) of rapeseed oil is greater compared to that of the cardoon oil, which does not contain significative quantities of linolenic acid (18:3). This accounts for the thermogram of the grapeseed oil to lean slightly towards lower temperatures, displaying a peak in a range of temperatures inferior to that of the cardoon oil.

Fig. 2c compares the variation of the solid content 


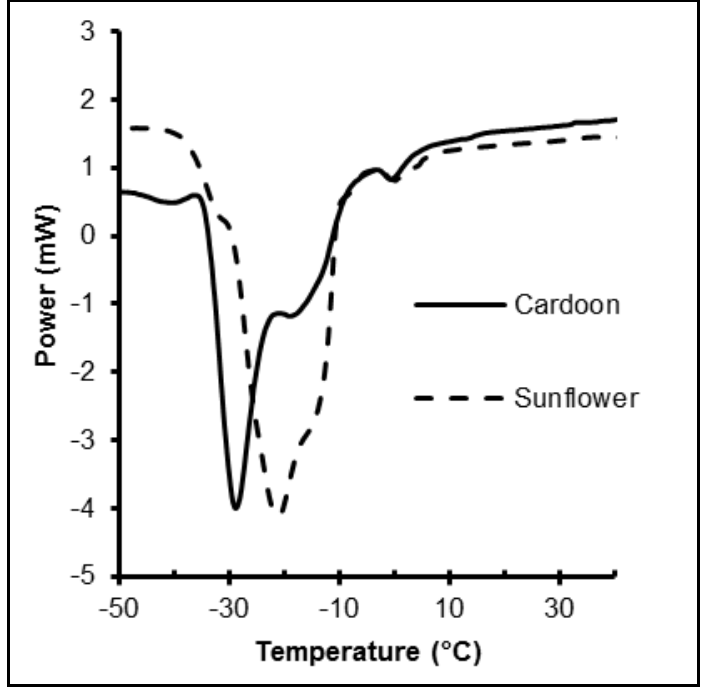

(a)

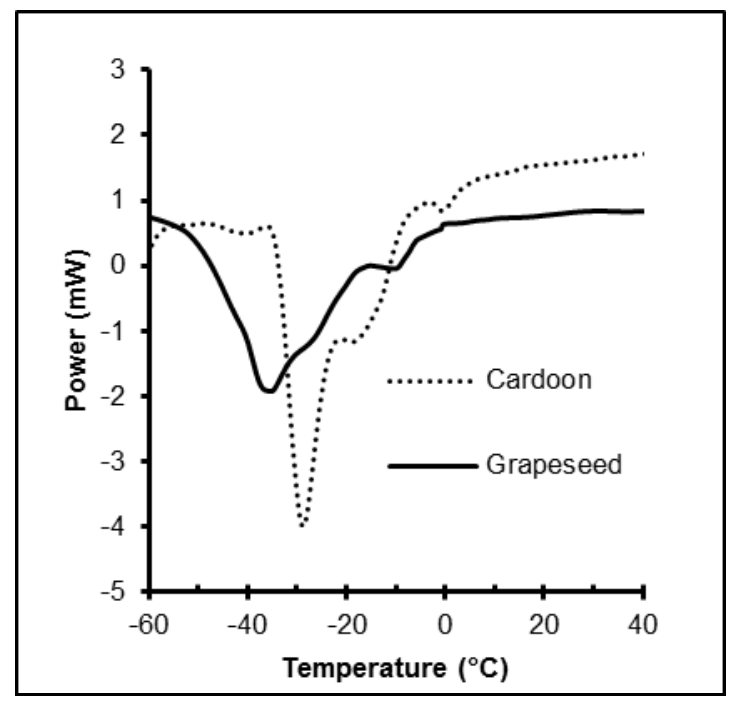

(b)

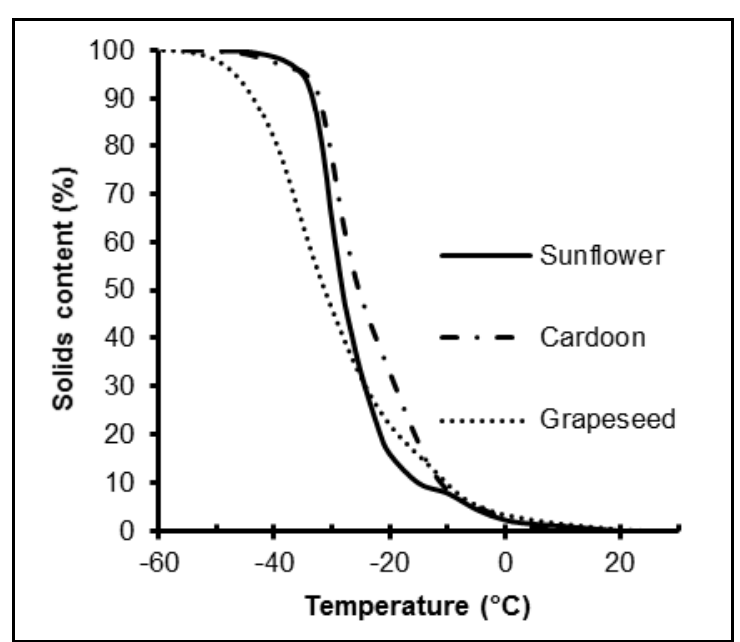

(c)

Fig. 2 Thermograms and variation of the solid content of cardoon, sunflower and grapeseed oils. of the cardoon, sunflower and grapeseed oils. All three oils show similar behavior, although the solids content of the sunflower oil is slightly lower than that of the cardoon, at any temperature. Therefore, from the thermal behavior point of view, one oil may substitute any of the other two.

Fig. 3a shows the thermograms for the cherimoya, papaya and avocado oils, all of which are native to tropical areas of America. The thermal behavior is very different for each oil sample, which is explained by their very different fatty acid composition (Table 1), as a consequence of their different triacylglycerols composition. Fig. $3 b$ shows the solid content of the three oils at different temperatures. In order to explain the thermal behavior based on their composition, each thermogram will be studied separately.

\subsubsection{Cherimoya Seed Oil}

The thermogram for the cherimoya seed oil is similar to that of the rapeseed oil (Fig. 4a), in spite of having different fatty acid composition (Table 1); cherimoya oil contains more palmitic and linoleic acids and less oleic and linolenic acids.

Due to its greater content of linolenic acid and smaller content of oleic acid, a greater proportion of more polyunsaturated triacylglycerols is expected, which would explain the slight movement of the peak towards lower temperatures. The presence of a shoulder to the right of the main peak could be explained by its greater content of saturated fatty acids leading to a greater content of the triacylglycerols that contain them. This results in a greater solid content at temperatures above $-25{ }^{\circ} \mathrm{C}$ (Fig. 4b). However, in temperatures above those, both oils present the same thermal behavior, with no turbidity under those cold conditions.

\subsubsection{Papaya Seed Oil}

The papaya seed oil's fatty acid composition (Fig. 5a) and thermal behavior (Fig. 5b) are similar to those of the high oleic sunflower oil. Both oils would not show turbidity when cold stored.

\subsubsection{Avocado Pulp Oil}

It is very interesting to see that the thermogram for the avocado oil shows two important peaks, which are 


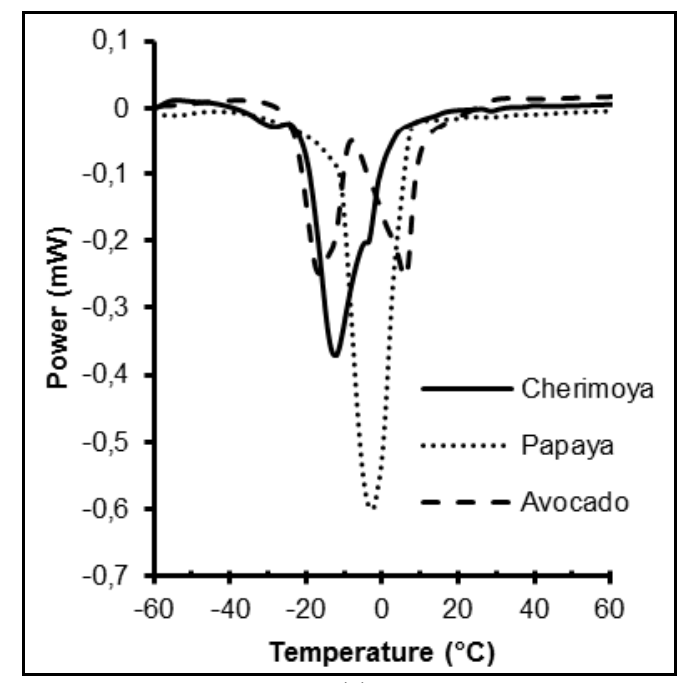

(a)

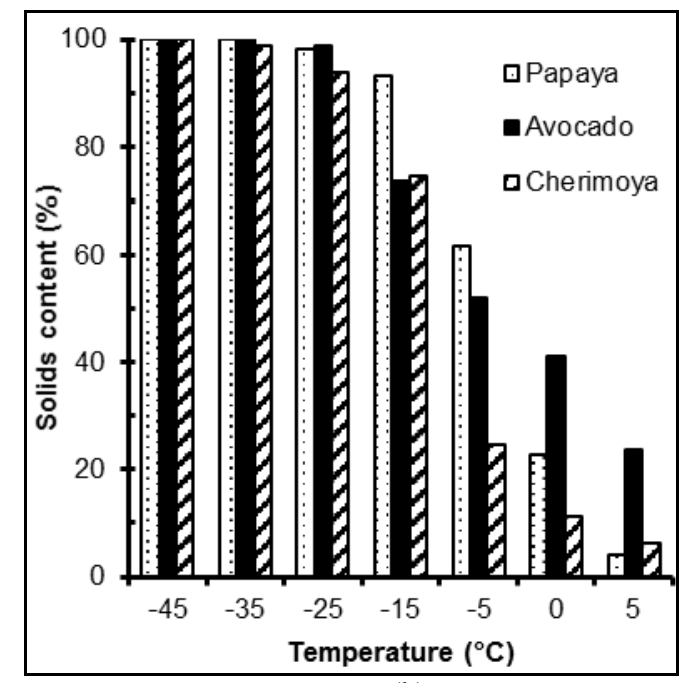

(b)

Fig. 3 Thermograms and variation of the solid content for the cherimoya, papaya and avocado oils.

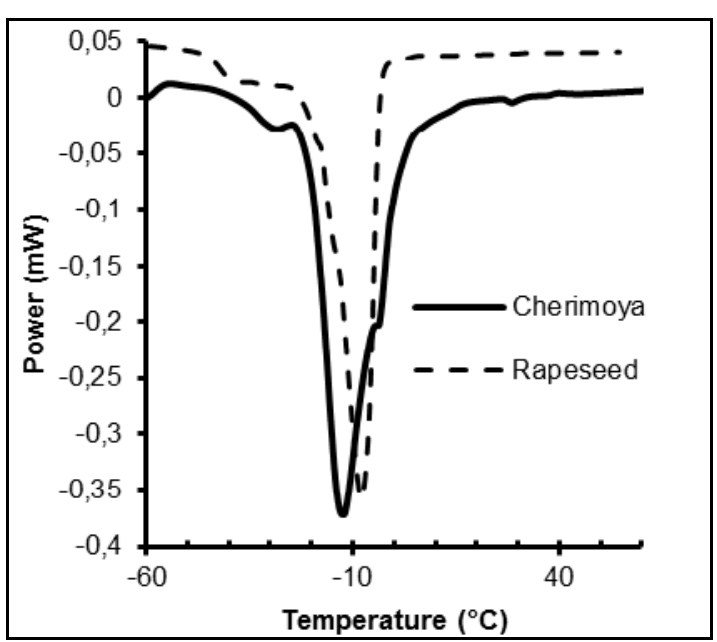

(a)

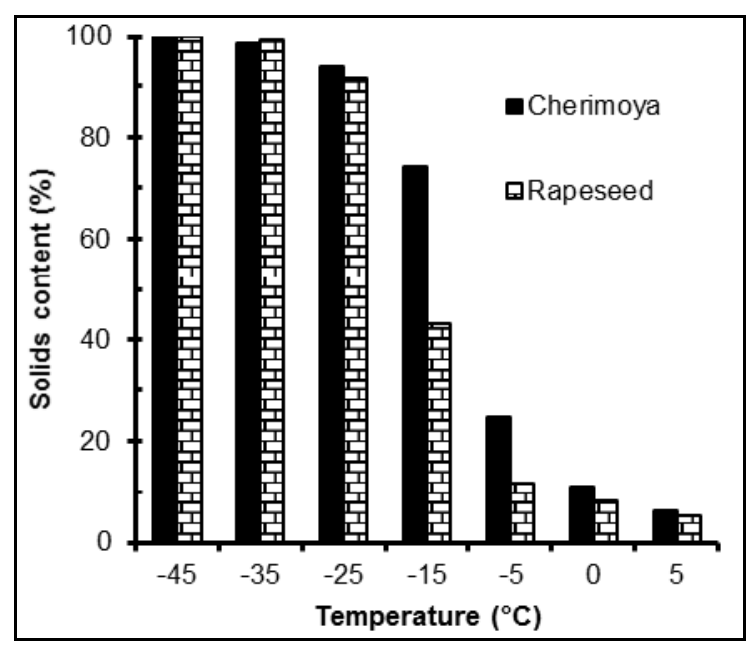

(b)

Fig. 4 Thermograms and variation of the solid content of three oils for the cherimoya and rapeseed oils.

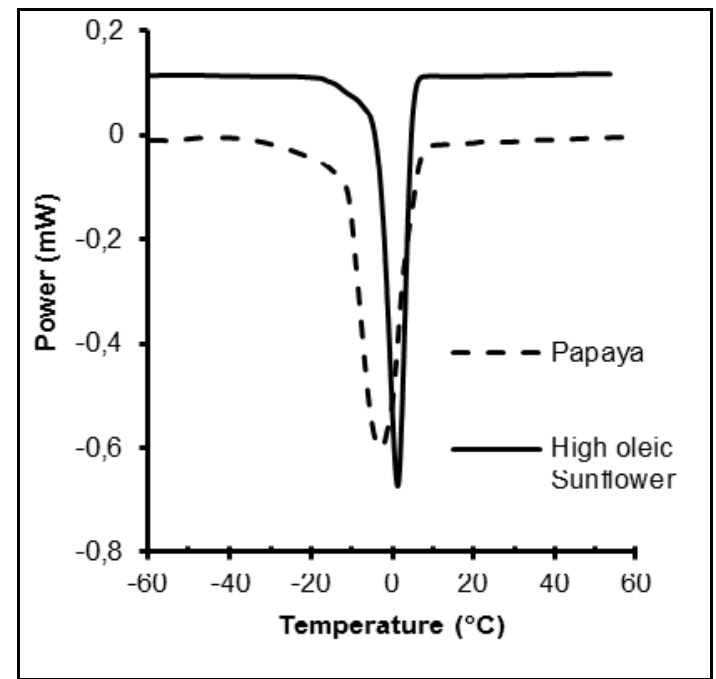

(a)

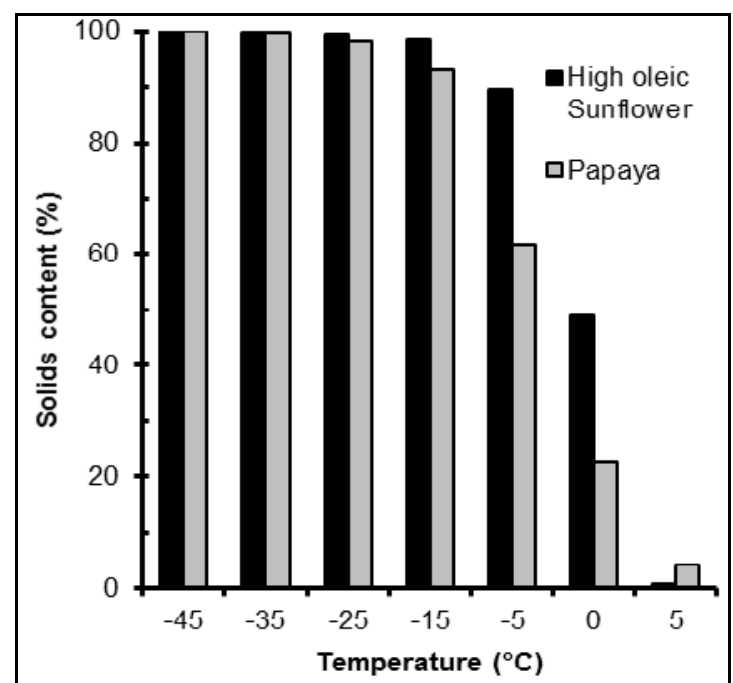

(b)

Fig. 5 Thermograms and variation of the solid content for the papaya and high oleic sunflower oils. 


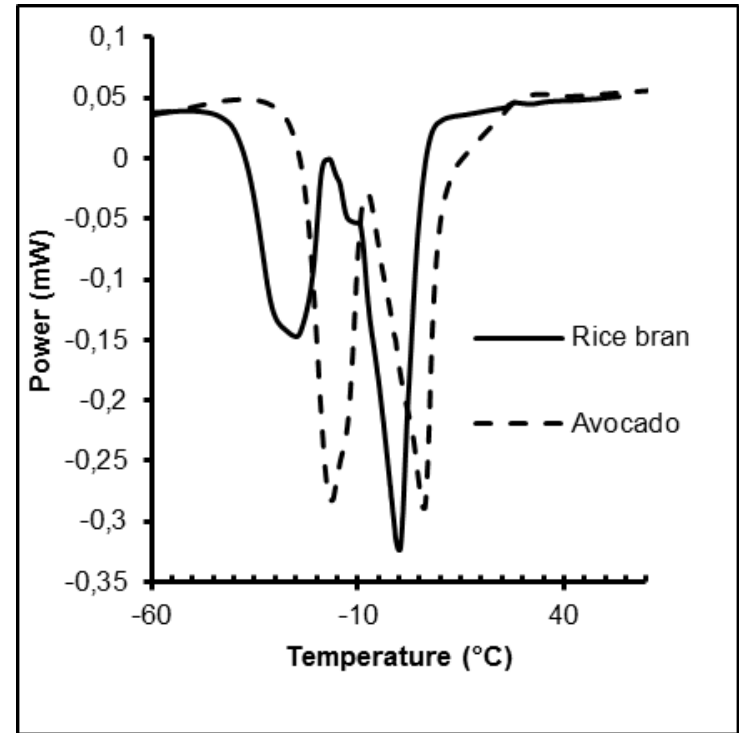

(a)

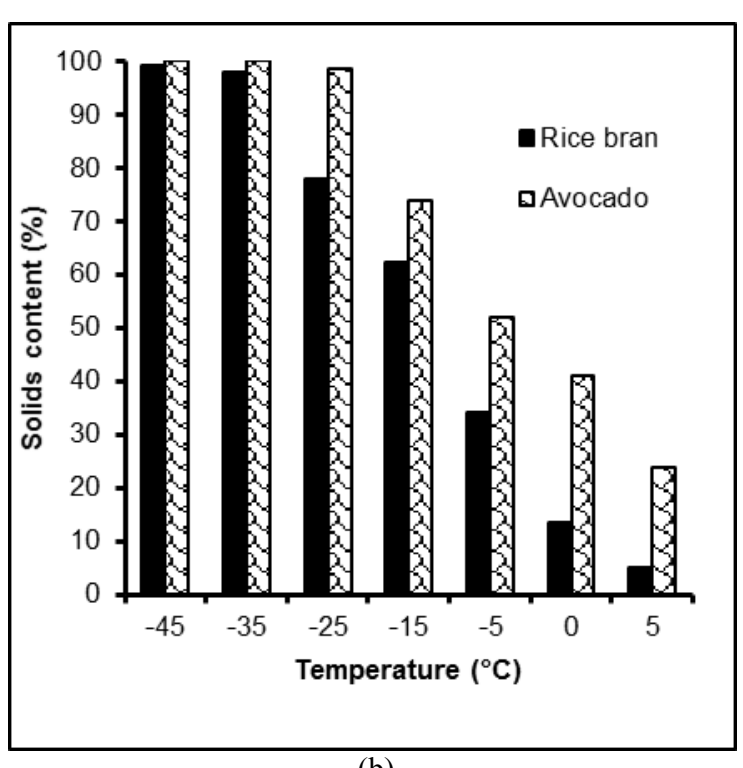

(b)

Fig. 6 Thermograms and variation of the solid content for rice bran and avocado pulp oils.

Table 2 Triacylglycerol composition for the oils of two varieties of avocado and one rice bran oil.

\begin{tabular}{llll}
\hline Triacylglycerol & Avocado (Hierro, 1992) & Avocado (Yanty, 2011-2012) & Rice bran (Irigaray, 2012) \\
\hline POP & 5.0 & 12.4 & 2.9 \\
POO & 31.0 & 22.8 & 12.5 \\
PLP & 1.0 & 4.0 & 4.9 \\
\hline Partial sum & 37.0 & 39.2 & 20.3 \\
\hline POL & 7.0 & 19.3 & 20.4 \\
SOL & 10.0 & & 10.3 \\
PLL & & 4.2 & 17.9 \\
OOL & 12.0 & 9.0 & 15.3 \\
OLL & 2.0 & 3.2 & 3.4 \\
LLL & & 0.9 & 67.3 \\
POLn + OOLn & 2.0 & & \\
\hline Partial sum & 33.0 & 36.6 & \\
\hline P & & &
\end{tabular}

$\mathrm{P}=$ palmitic; $\mathrm{S}=$ estearic; $\mathrm{O}=$ oleic; $\mathrm{L}=$ linoleic; $\mathrm{Ln}=$ linolenic.

are relatively separated. This would indicate the presence of two groups of triacylglycerides with relatively different melting characteristics. The thermogram for the rice bran oil also presents two peaks. Fig. 6 shows both thermograms superimposed.

Hierro et al. [33] studied the triacylglycerol composition of the avocado oil. Yanty et al. [34] studied the varietal effect on the triacylglycerol composition and the thermal behavior of the avocado oil. The heating thermograms presented an important peak between $-20{ }^{\circ} \mathrm{C}$ and $-10{ }^{\circ} \mathrm{C}$ and a smaller one at higher temperatures. This thermal behavior is similar to the one determined in this paper. Yanty et al. [34] also studied the triacylglycerol composition and thermal behavior of the avocado butter compared to other oils and lard. Based on the above mentioned bibliography, Table 2 was made to group the triacylglycerols, approximately, based on whether their melting points were above or below $0{ }^{\circ} \mathrm{C}$. The triacylglycerols composition of the rice bran oil [35] was also included, as its thermogram also showed two peaks. The content of the OOO triacylglycerols $(\mathrm{O}=$ oleic) was omitted, as it would fall between the previously mentioned peaks of the thermogram. The values in this table explain, approximately, the presence of two peaks of similar size in the 
thermogram of the avocado oil and a small peak as well as a bigger one in the thermogram of the rice bran oil.

Fig. $6 \mathrm{~b}$ shows the variation of the solid content in avocado and rice bran oils in relation to their temperature. The solid content of the rice bran oil, at any temperature, is lower than that of the avocado oil, which is explained by the higher content of unsaturated triacylglycerols (PLL, OOL, OLL and LLL; where $\mathrm{P}=$ palmitic, $\mathrm{L}=$ linoleic and $\mathrm{O}=$ oleic) of the rice bran oil. The avocado oil presents a higher solid content at cold store or winter temperatures than that of the rice bran oil, which would make its use difficult when stored in those conditions.

\section{Conclusions}

Commercial chia oils did not present any discernible variation in neither their fatty acid composition nor their thermal behavior. This oil, due to its high content of 18:3 fatty acid, belonging to the omega-3 family, presents important nutritional advantages; but also due to a very low oxidative stability, it needs to be protected from oxidation by adding antioxidants and/or being refrigerated and/or encapsulated. The oils almost null solid content at cold store temperatures make its storage in those conditions possible.

The analyzes of other oils extracted by cardoon, grapeseed, papaya, cherimoya and avocado present different thermal behaviors. When compared to commercial oils of similar composition (virgin olive oil, regular sunflower oil, high oleic sunflower oil, rice bran oil, rapeseed oil and soybean oil), some similarities and differences were observed in the thermal behavior which are related to their compositions. The avocado oil, in particular, presents high solid content at cold store or winter temperatures, which would make its use difficult in those conditions (for example, a cosmetic cream or gourmet oil).

In conclusion, the thermal behavior of one oil sample as determined by DSC provides valuable information with regards to the possible use of new oils of American origin as replacement of usual commercial others.

\section{References}

[1] Ayerza, R. 1995. "Oil Content and Fatty Acid Composition of Chia (Salvia hispanica L.) from Five Northwestern Locations in Argentina." J. Amer. Oil Chem. Soc. 72 (9): 1079-81.

[2] Coates, W., and Ayerza, R. 1996. "Production Potential of Chia in Northwestern Argentina." Ind. Crops Prod. 5 (3): 229-33.

[3] Coates, W., and Ayerza, R. 1998. "Commercial Production of Chia in Northwestern Argentina." J. Amer. Oil Chem. Soc. 75 (10): 1417-20.

[4] Heuer, B., Yaniv, Z., and Ravina, I. 2002. "Effect of Late Salinization of Chia (Salvia hispanica L.), Stock (Matthiola tricuspidata) and Evening Primrose (Oenothera biennis) on Their Oil Content and Quality." Ind. Crops Prod. 15 (2): 163-7.

[5] Ayerza, R., and Coates, W. 2004. "Protein and Oil Content, Peroxide Index and Fatty Acid Composition of Chia (Salvia hispanica L.) Grown in Six Tropical and Sub-tropical Ecosystems of South America." Trop. Sci. 44 (3): 131-5.

[6] Ayerza, R., and Coates, W. 2009. "Influence of Environment on Growing Period and Yield, Protein, Oil and $\alpha$-Linolenic Content of Three Chia (Salvia hispanica L.) Selections." Ind. Crops and Prod. 30 (2): 321-4.

[7] Peiretti, P. G., and Gai, F. 2009. "Fatty Acid and Nutritive Quality of Chia (Salvia hispanica L.) Seeds and Plant during Growth." Animal Feed Sci. Technol. 148 (2-4): 267-75.

[8] Ixtaina, V. Y., Martínez, M. L., Spotorno, V., Mateo, C. M., Maestri, D. M., Diehl, B. W. K., Nolasco, S. M., and Tomás, M. C. 2011. "Characterization of Chia Seed Oil Obtained by Pressing and Solvent Extraction." J. Food Comp. Anal. 24 (2): 166-74.

[9] Werman, M. J., and Neema, I. 1987. "Avocado Oil Production and Chemical Characteristics." J. Amer. Oil Chem. Soc. 64 (2): 229-32.

[10] Swisher, H. E. 1988. "Avocado Oil: From Food Use to Skin Care.” J. Amer. Oil Chem. Soc. 65 (11): 1704-6.

[11] Martínez-Nieto, L., Barranco-Barranco, R., and Moreno-Romero, M. V. 1992. "Avocado Oil Extraction: An Industrial Experiment.” Grasas y Aceites 43 (1): 11-5.

[12] Werman, M. J., Mokady, S., and Neeman, I. 1996. "A Simple and Sensitive Method for Detecting Avocado Seed Oil in Various Avocado Oils." J. Amer. Oil Chem. Soc. 73 (5): 665-7. 
[13] Bora, P. S., Narain, N., Rocha, R. V. M., and Queiroz-Paulo, M. 2001. "Characterization of the Oils from the Pulp and Seeds of Avocado (Cultivar: Fuerte) Fruits." Grasas y Aceites 52 (3-4): 171-4.

[14] Ozdemir, F., and Topuz, A. 2004. "Changes in Dry Matter, Oil Content and Fatty Acids Composition of Avocado during Harvesting Time and Post-Harvesting Ripening Period.” Food Chem. 86 (1): 79-83.

[15] Villa-Rodríguez, J. A., Molina-Corral, F. J., Ayala-Zavala, J. F., Olivas, G. I., and González-Aguilar, G. A. 2011. "Effect of Maturity Stage on the Content of Fatty Acids and Antioxidant Activity of 'Hass' Avocado." Food Res. Int. 44 (5): 1231-7.

[16] Yanty, N. A. M., Marikkar, J. M. N., and Long, K. 2011. "Effect of Varietal Differences on Composition and Thermal Characteristics of Avocado Oil." J. Am. Oil Chem. Soc. 88 (12): 1997-2003.

[17] Berasategi, I., Barriuso, B., Ansorena, D., and Astiasarán, I. 2012. "Stability of Avocado Oil during Heating: Comparative Study to Olive Oil." Food Chem. 132 (1): 439-46.

[18] Madawala, S. R. P., Kochhar, S. P., and Dutta, P. C. 2012. "Lipid Components and Oxidative Status of Selected Specialty Oils." Grasas y Aceites 63 (2): 143-51.

[19] Marfo, E. K., Oke, O. L., and Afolabi, O. A. 1986. "Chemical Composition of Papaya (Carica papaya) Seeds." Food Chem. 22 (4): 259-66.

[20] Ucciani, E. 1995. New Dictionary of Vegetable Oils. Paris, France: Technique et Documentation-Lavoisier.

[21] Firestone, D., ed. 2006. Physical and Chemical Characteristics of Oils, Fats and Waxes, 2nd ed.. Washington, USA: AOCS Press.

[22] Raccuia, S. A., Piscioneri, I., Sharma, N., and Melilli, M. G. 2011. "Genetic Variability in Cynara cardunculus L. domestic and Wild Types for Grain Oil Production and Fatty Acids Composition.” Biomass and Bioenergy 35 (7): 3167-73.

[23] El-Shami, S. M., El-Mallah, M. H., and Mohamed, S. S. 1992. "Studies on the Lipid Constituents of Grapeseeds Recovered from Pomace Resulting from White Grape Processing." Grasas y Aceites 43 (3): 157-60.

[24] Bail, S., Stuebiger, G., Krist, S., Unterweger, H., and Buchbauer, G. 2008. "Characterization of Various Grapeseed Oils by Volatile Compounds, Triacylglycerol Composition, Total Phenols and Antioxidant Capacity."
Food Chem. 108 (3): 1122-32.

[25] Fernández, C., Ramos, M. J., Pérez, A., and Rodríguez, J. F. 2010. "Production of Biodiesel from Winery Waste: Extraction, Refining and Transesterification of Grapeseed Oil." Biores. Technol. 101 (18): 7019-24.

[26] Passos, C. P., Silva, R. M., Da Silva, F. A., Coimbra, M. A., and Silva, C. M. 2010. "Supercritical Fluid Extraction of Grapeseed (Vitis vinifera L.) Oil: Effect of the Operating Conditions upon Oil Composition and Antioxidant Capacity." Chem. Eng. J. 160 (2): 634-40.

[27] Lutterodt, H., Slavin, M., Whent, M., Turner, E., and Yu, L. 2011. "Fatty Acid Composition, Oxidative Stability, Antioxidant and Antiproliferative Properties of Selected Cold-Pressed Grapeseed Oils and Flours." Food Chem. 128 (2): 391-9.

[28] Hanganu, A., Todasca, M. C., Chira, N. A., Maganu, M., and Rosca, S. 2012. "The Compositional Characterization of Romanian Grapeseed Oils Using Spectroscopic Methods." Food Chem. 134 (4): 2453-8.

[29] Höhne, G., Hemminger, W., and Flammersheim, H. J. 1995. Differential Scanning Calorimetry. New York, USA: Springer.

[30] Timms, R. E. 2003. "Physical Chemistry." In Confectionery Fats Handbook: Properties, Production and Application. Bridgwater, UK: The Oily Press.

[31] Association of Official Analytical Chemists (AOAC). 1990. Official Methods of Analysis, 15th ed.. USA: AOAC.

[32] AOCS. 1990. Official Methods and Recommended Practices of the American Oil Chemists' Society, 4th ed.. Champaign, USA: AOCS.

[33] Hierro, M. T. G., Tomás, M. C., Fernández-Martín, F., and Santa-María, G. 1992. "Determination of the Triglyceride Composition of Avocado Oil by High-Performance Liquid Chromatography Using a Light-Scattering Detector." J. Chromatogr. 607 (2): 329-38.

[34] Yanty, N. A. M., Marikkar, J. M. N., and Miskandar, M. S. 2012. "Comparing the Thermo-Physical Characteristics of Lard and Selected Plant Fats." Grasas y Aceites 63 (3): 328-34.

[35] Irigaray, B. 2012. "Obtaining and Characterizing of Gamma-Oryzanol for Use in the Food Industry." Ph.D. thesis, Universidad de la República, Montevideo, Uruguay. 